\title{
Time Course of the Response of Myofibrillar and Sarcoplasmic Protein Metabolism to Unweighting of the Soleus Muscle
}

\author{
Kathryn A. Munoz, Soisungwan Satarug, and Marc E. Tischler
}

\begin{abstract}
Contributions of altered in vivo protein synthesis and degradation to unweighting atrophy of the soleus muscle in tail-suspended young female rats were analyzed daily for up to 6 days. Specific changes in myofibrillar and sarcoplasmic proteins were also evaluated to assess their contributions to the loss of total protein. Synthesis of myofibrillar and sarcoplasmic proteins was estimated by intramuscular (IM) injection and total protein by intraperitoneal (IP) injection of flooding doses of ${ }^{3} \mathrm{H}$-phenylalanine. Total protein loss was greatest during the first 3 days following suspension and was a consequence of the loss of myofibrillar rather than sarcoplasmic proteins. However, synthesis of total myofibrillar and sarcoplasmic proteins diminished in parallel beginning in the first $\mathbf{2 4}$ hours. Therefore sarcoplasmic proteins must be spared due to a decrease in their degradation. In contrast, myofibrillar protein degradation increased, thus explaining the elevated degradation of the total pool. Following 72 hours of suspension, protein synthesis remained low, but the rate of myofibrillar protein loss diminished, suggesting a slowing of degradation. These various results show (1) acute loss of protein during unweighting atrophy is a consequence of decreased synthesis and increased degradation of myofibrillar proteins, and (2) sarcoplasmic proteins are spared due to slower degradation, likely explaining the sparing of plasma membrane receptors. Based on other published data, we propose that the slowing of atrophy after the initial response may be attributed to an increased effect of insulin.
\end{abstract}

Copyright 1993 by W.B. Saunders Company

$\mathbf{A}^{\mathrm{T}}$ TROPHY OF THE SOLEUS muscle by unweighting is associated with decreased protein synthesis and increased protein degradation when measured either in vivo $^{1-4}$ or in vitro ${ }^{3.5 .6} ;$ an extensive comparison of these studies has been made in a recent review. ${ }^{7}$ Using in vivo protein synthesis measurements and a numeric model for estimating protein degradation, Thomason et $\mathrm{a}^{4.7}$ have evaluated the time course for changes in protein metabolism in unweighted soleus muscle of adult female rats. They concluded that following unweighting, protein degradation increases after an initial rapid decrease in protein synthesis; for adult animals, the increase in protcolysis is transient, peaking after 2 weeks. ${ }^{4}$

Nevertheless, our knowledge of the relative contributions of decreased protein synthesis and increased protein degradation to protein loss following unweighting remains limited and is confounded by potential differences due to the model system used. For harness-suspended young male rats, Goldspink et $\mathrm{al}^{1}$ and Loughna et $\mathrm{al}^{2}$ analyzed in vivo protein turnover on the fifth and third days after unweighting, respectively. The soleus atrophied an average of $14 \% / \mathrm{d}$ (days 1 to 3 ) and $22 \% / d$ (days 3 to 5); most of this atrophy could be accounted for by a twofold to threefold increase in the estimated rate of breakdown. During tail suspension of young male rats for 4 or 6 days, the increase in estimated in

From the Department of Biochemistry, University of Arizona Health Sciences Center, and Graduate Program in Nutritional Sciences, Tucson, $A Z$.

Submitted May 29, 1992; accepted October I4, 1992.

Supported in part by Grant No. NAG2-384 from the National Aeronautics and Space Administration (NASA). Portions of this study were conducted during the tenure of a NASA Graduate Researchers Program Fellowship to Kathryn A. Munoz.

Present address: S.S., Department of Biochemistry, Faculty of Medicine, Khon-Kaen University, Thailand.

Address reprint requests to Marc E. Tischler, PhD, Department of Biochemistry, University of Arizona, Tucson, AZ 85724.

Copyright $\odot 1993$ by W.B. Saunders Company

0026-0495/93/4208-0014\$03.00/0 vivo degradation accounted for only about half of the overall atrophy. ${ }^{3}$ Likewise, numeric modeling predicted approximately a $50 \%$ increase in the fractional degradation rate after 7 days of tail suspension of adult female rats. ${ }^{4}$ This difference in the contribution of proteolysis between models may reflect a catabolic effect of corticosterone in harness-suspended animals, which have greater circulating levels of this steroid ${ }^{8}$ than tail-suspended rats. ${ }^{4}$ The additional stress with harness suspension is evidenced by increased protein breakdown in the extensor digitorum longus muscle, ${ }^{2}$ which is generally unresponsive to unweighting of hindlimbs by tail suspension. ${ }^{3,5-7}$

Some studies also have examined specific contributions of myofibrillar proteins to atrophy caused by unweighting. These studies have demonstrated a relative loss of myofibrillar proteins over periods of unweighting ranging from 4 days to 8 weeks in soleus muscle of adult female rats. ${ }^{10-13}$ In these muscles, myofibrillar proteins show decreased synthesis for at least 4 weeks and increased degradation for up to 3 weeks. ${ }^{4}$ Thus the prolonged ( 3 to 8 weeks) loss of myofibrillar proteins scems to be largely a result of slower synthesis. In several reports from this laboratory, we have demonstrated a preferential acute ( $\leq 6$ days) loss of myofibrillar proteins in unweighted soleus of young male and female rats. ${ }^{3,6.14}$ Results from these studies also suggested no loss or at least only a modest loss of sarcoplasmic proteins on the basis of increased protein concentration, no change in protein content, and decreased ratio of myofibrillar to sarcoplasmic proteins after 6 days of unweighting. In accord with this idea, insulin and $\beta$-adrenergic receptors of unweighted soleus show an increase in receptor density, probably due to a preferential loss of myofibrillar proteins. ${ }^{15,16}$ Since measurement of in vitro sarcoplasmic protein synthesis suggested a reduced rate of synthesis of these proteins in unweighted soleus muscle, it is hypothesized that degradation of these proteins must decrease in parallel.

We examined the sequence of acute daily ( 1 to 4 days) changes in protein metabolism to study the pattern of 

atrophy of unweighted soleus muscle. This was accomplished by measuring muscle protein content and fractional rates of protein synthesis in vivo using intraperitoneal (IP) injection of a flooding dose of ${ }^{3} \mathrm{H}$-phenylalanine and estimating degradation as the difference between synthesis and growth. ${ }^{17.18}$ Second, we considered the relative contributions of myofibrillar and sarcoplasmic protein pools to the changes in total protein. Protein content and fractional rates of their synthesis were measured daily, and degradation was calculated. To facilitate labeling and analysis of the small pool of sarcoplasmic proteins without drastically increasing the number of animals used, the flooding-dose technique was modified for use by intramuscular (IM) injection of radiolabeled phenylalanine.

\section{MATERIALS AND METHODS}

\section{Treatment of Animals}

All procedures were approved by the University of Arizona Animal Care and Use Committee. Juvenile female rats (105 to 135 g; Sasco Sprague-Dawley, Omaha, NE) were maintained on food and water ad lihitum. Animals were killed by cervical dislocation; body weights of animals were measured before tail casting and at the time of killing. During all potentially stressful procedures (eg, tailcasting), animals were tranquilized by forelimb muscle injection of $0.1 \mathrm{~mL} / 100 \mathrm{~g}$ body weight $10 \%$ (vol/vol) Innovar-vet $(4 \mu \mathrm{g}$ Sublimaze, $200 \mathrm{\mu g}$ Inapsine; Pitman-Moore, Washington Crossing. NJ). Animals were tail-casted and suspended in a head-down position so that their hindlimbs were elevated above the floor of the cage for the period indicated. ${ }^{5}$ Tail casts consisted of Hexcelite orthopedic tape (Kirschner Medical, Timonium, MD) and medical grade elastomer (Factor II, Lakeside, AZ). Control (weighthearing) animals for the total protein studies also were tail-casted; since this potential stressor did not alter their growth, subsequent controls were not tail-casted.

\section{Protein Accretion or Loss}

To study changes in total mixed proteins of soleus muscle, we measured protein content, protein synthesis, and muscle mass for animals suspended 1 to 6 days. Protein samples were collected from the same muscles used for assessing protein synthesis, as described in the following section. For each period, the extent of growth (protein accretion) or atrophy (protein loss) was hased on the change in protein content. For each muscle, percent change of protein was calculated as the difference between the measured value at the end of each period and the estimated value for the day of suspension. Initial protein content (normal animals) was calculated using a standard plot of soleus protein content versus body weight (Fig 1A). Thus initial body weights could be used to estimate protein content at time zero (time of suspension) from the regression equation. For simplicity, the time point at which suspension was initiated is heretofore referred to as the control value. The fractional growth rate (percent/day) for each successive 24-hour period was calculated as the difference in the percent change for the appropriate periods of time. For example, the growth rate for day 2 , which is the period commencing at 24 hours and ending at 48 hours after suspension, was calculated as the difference in the percent change between 48 hours and 24 hours of unweighting. Protein values were normalized to the average initial weight of all animals in an experiment. Protein data are presented as percent change in protein content over time, which is corrected for body weight differences, rather than as absolute value of protein content.

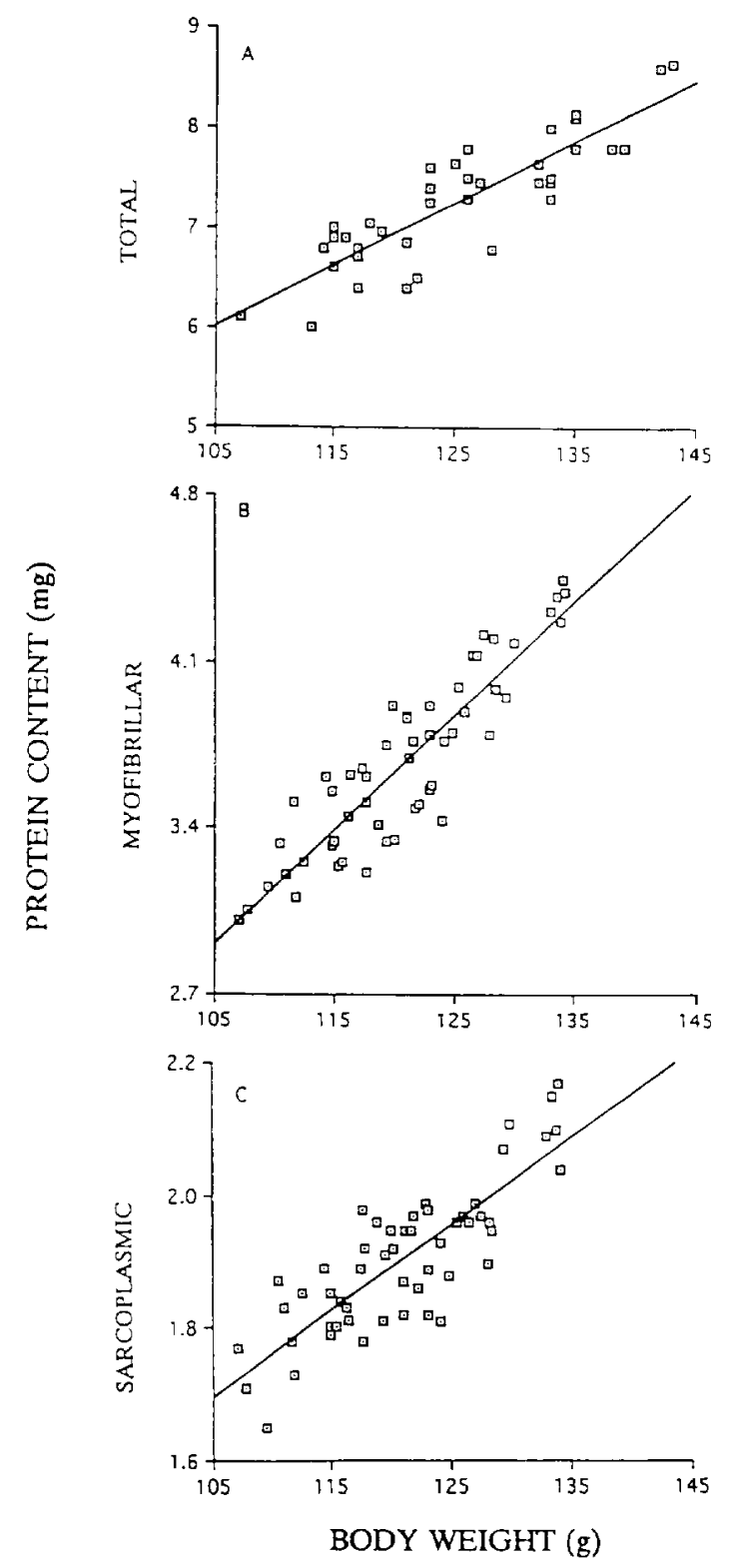

Fig 1. Relationship of total (A), myofibrillar (B), and sarcoplasmic (C) proteins in soleus muscle to animal body weight. Linear regression analysis was performed on muscles from $\mathbf{3 7}$ animals for total protein and from $\mathbf{5 3}$ animals for myofibrillar and sarcoplasmic proteins. Equations for the lines were as follows: total protein $=(.062 \times$ body weight $)-0.53, R^{2}=.76$; myofibrillar protein $=(.048 \times$ body weight $)$ $-2.15, R^{2}=.81 ;$ sarcoplasmic protein $=(.013 \times$ body weight $)-.32$, $R^{2}=.70$.

The procedure used for separating protein fractions was based on a published method. ${ }^{19}$ Muscles were excised, weighed, and then homogenized in $3 \mathrm{~mL}$ ice-cold $10 \mathrm{mmol} / \mathrm{L}$ Tris hydrochloride buffer, pH 7.4, containing $5 \mathrm{mmol} / \mathrm{L}$ cycloheximide (BoehringerMannheim, Indianapolis, IN). Cycloheximide was added to terminate protein synthesis after excising the muscle. ${ }^{21}$ Muscle homogenates were centrifuged at $2,800 \times g$ for 5 minutes and then at $10,000 \times g$ for 20 minutes at $4^{\circ} \mathrm{C}$. The protein pellet (myofibrillar fraction) was washed three times with $1 \mathrm{~mL}$ buffer, and supernatant solutions (sarcoplasmic fraction) from the centrifugations 
were pooled (6 mL final volume). Sarcoplasmic proteins were precipitated by addition of $1 \mathrm{~mL}$ ice-cold $100 \%$ (w//vol) trichloroacetic acid (TCA) to pooled supernatant solutions followed by centrifugation as previously described. Both protein pellets were washed with $2 \mathrm{~mL}$ ethanol:ether (1:1) and then solubilized in $2 \mathrm{~mL}$ $1 \mathrm{~mol} / \mathrm{L} \mathrm{NaOH}$. Protein content was determined using the Lowry method with bovine serum albumin as the standard. ${ }^{21}$ Estimation of fractional rates of protein accretion or loss was the same as that described for total proteins. Standard plots for soleus myofibrillar or sarcoplasmic proteins versus body weight were used in calculating protein values at time zero (Fig $1 B$ and $C$, respectively).

\section{Estimation of Protein Synthesis and Degradation}

Fractional rates (percent/day) of in vivo protein synthesis and degradation were assessed by using a flooding dose of $\mathrm{L}$-[side chain $-{ }^{3} \mathrm{H}$ ] phenylalanine (ICN, Costa Mesa, CA). The fractional rate of degradation is calculated as the difference between the fractional rate of synthesis and fractional rate of protein accretion for a 24-hour period, as previously described. Final data for fractional growth (or atrophy), synthesis, and degradation are approximations for each 24 -hour period.

\section{Total Mixed Protein Synthesis}

Procedures for estimating protein synthesis represent adaptations from original methods described elsewhere. ${ }^{17,18}$ Intracellular specific activity was used for calculating the fractional rate of synthesis of total mixed proteins. For each experiment, animals were tranquilized as described above and then injected IP with 300 $\mu \mathrm{mol}$ and $40 \mu \mathrm{Ci}{ }^{3} \mathrm{H}$-phenylalanine administered in $2 \mathrm{~mL} 1 \%$ saline solution $/ 100 \mathrm{~g}$ body weight. Fifteen minutes later, soleus muscles were removed and frozen in liquid nitrogen to terminate protein synthesis; both muscles were excised within 75 seconds. Comparative measurements of the first or second muscle excised show no difference in the results. ${ }^{3}$

Specific activities of free intracellular $\left(S_{i}\right)$ and protein-bound $\left(S_{\mathrm{h}}\right)$ phenylalanine were determined as described elsewhere, ${ }^{17}$ with modifications restricted to the volumes used. ${ }^{3}$ The fractional rate of synthesis was calculated as $S_{b} /\left(0.9 \cdot S_{i} \cdot t\right)$, where $t$ is the time in days between injection and muscle excision. ${ }^{18}$

\section{Myofibrillar and Sarcoplasmic Protein Synthesis}

Measurement of fractional synthesis rates of separate myofibrillar and sarcoplasmic protein fractions was problematic largely because of the small pool of sarcoplasmic proteins. Hence we modified the flooding-dose method to entail IM rather than IP injection; we have previously used IM injections to successfully test in situ effects of protease inhibitors ${ }^{22}$ and hormones. ${ }^{16}$ As adapted from Gerard et al, ${ }^{23}$ a $5-\mathrm{mm}$ incision was made in the outer side of the shaved hindlimb of etherized rats. After the underlying fascia was cut, the soleus was gently exposed by hooking it with fine curved forceps. The belly of the muscle was injected with L-[side chain $\left.-{ }^{3} \mathrm{H}\right]$ phenylalanine $(50 \mathrm{mmol} / \mathrm{L}, \sim 4 \mu \mathrm{Ci})$ contained in 150 mmol/ $\mathrm{L} \mathrm{NaCl}$ using a $10-\mu \mathrm{L}$ Hamilton syringe. The volume injected depended on muscle size, as follows: $4 \mu \mathrm{L} / 100 \mathrm{~g}$ body weight for control muscles, $3.8 \mu \mathrm{L} / 100 \mathrm{~g}$ body weight for 1 - or 2-day unweighted muscles, and $3.2 \mu \mathrm{L} / 100 \mathrm{~g}$ body weight for 3-or 4-day unweighted muscles. Average muscle sizes were obtained from studies in which only protein content was analyzed.

To determine distribution of radioactivity, 15 minutes after injection both soleus muscles from six animals were excised and the ends separated from the middle; data for right and left muscles were averaged. The two ends and the middle piece were each homogenized in $1.5 \mathrm{~mL} 5 \%$ TCA and then centrifuged for 15 minutes at $2,800 \times g$. Pellets were washed with $1 \mathrm{~mL} 5 \% \mathrm{TCA}$ and then solubilized in $2 \mathrm{~mL} 1 \mathrm{~mol} / \mathrm{L} \mathrm{NaOH}$. A $0.5-\mathrm{mL}$ aliquot was counted in $5 \mathrm{~mL}$ aqueous counting solution, and $1 \mathrm{~mL}$ was used for protein analysis using the biuret procedure with bovine serum albumin as the standard. ${ }^{24}$

For measuring fractional rates of myofibrillar and sarcoplasmic protein synthesis, animals were injected and muscles were excised and rinsed in $3 \mathrm{~mL} 20 \mathrm{mmol} / \mathrm{L}$ cycloleucine (Sigma Chemical, St Louis, MO) and $5 \mathrm{mmol} / \mathrm{L}$ cycloheximide contained in ice-cold $1 \%$ saline, as justified in the Results. Cycloleucine, which is transported on the L-system in muscle, ${ }^{25}$ was added to prevent leakage of intracellular phenylalanine; cycloheximide was added to inhibit protein synthesis. ${ }^{2 n}$ Muscles were then homogenized in $2 \mathrm{~mL}$ ice-cold $10 \mathrm{mmol} / \mathrm{L}$ Tris buffer, $\mathrm{pH} 7.4$, containing $5 \mathrm{mmol} / \mathrm{L}$ cycloheximide, and centrifuged at $2,800 \times \mathrm{g}$ for 5 minutes followed by 20 minutes at $10,000 \times g$. The protein pellet (myofibrillar) was washed four times with $1 \mathrm{~mL}$ buffer, and supernatants were pooled ( $6 \mathrm{~mL}$ total volume). Sarcoplasmic proteins were precipitated by adding $1 \mathrm{~mL} 8 \%$ perchloric acid to pooled supernatant solutions. After centrifugation, as immediately above, the pellet was washed once with $2 \mathrm{~mL} 2 \%$ perchloric acid. A $2-\mathrm{mL}$ aliquot of the initial supernatant solution (acid-soluble fraction) was processed for estimation of intracellular specific activity, as for total specific activity. ${ }^{17.18}$ Protein pellets also were processed and analyzed as for total protein (see protein accretion or loss). Fractional rates of synthesis were calculated as $S_{h} /\left(S_{i} \cdot t\right)$.

\section{Statistical Analysis}

The calculated fractional rate of degradation for specific 24-hour periods is based on calculations from mean measured values of protein content and fractional synthesis at the beginning and end of that period. Therefore, they do not lend themselves to determination of standard errors of measurement; for this reason, such data are analyzed qualitatively. Significance was tested for percent changes in protein content or for fractional rates of synthesis measured at a given time. Data are expressed as means \pm SEM, and one-way ANOVA was performed with Bonferroni correction.

\section{RESULTS}

\section{Body Weight and Food Consumption}

In the course of various studies, this laboratory has considered the problem of differences in body weight gain and food consumption by tail-suspended animals. The change in body weight over a 4-day period was $18.6 \% \pm$ $2.7 \%$ in weight-bearing animals and $12.6 \% \pm 1.8 \%$ in suspended animals. Although suspended animals gain less weight, they consume similar amounts of food; the lower weight gain reflects the minor stress of suspension. ${ }^{5,6,9}$

\section{Time Course of Protein Changes}

Protein accumulation in control (weight-bearing) animals averaged $5.2 \% \pm 0.5 \% / \mathrm{d}$ for total mixed proteins, $4.4 \% \pm 0.4 \% / \mathrm{d}$ for myofibrillar proteins, and $4.9 \% \pm$ $0.5 \% / \mathrm{d}$ for sarcoplasmic proteins. These values did not differ even though data for total mixed proteins and myofibrillar and sarcoplasmic proteins were gathered from different groups of control animals several years apart.

The time course of cumulative changes in protein content for these protein pools following unweighting of the soleus showed that the loss of myofibrillar proteins paralleled the decrease in total mixed proteins (Table 1). Following the first day of unweighting, there was neither accretion nor 
Table 1. Effect of Unweighting on Changes in Total, Myofibrillar, and Sarcoplasmic Protein Content

\begin{tabular}{cccr}
\hline \multirow{2}{*}{$\begin{array}{c}\text { Duration of } \\
\text { Unweighting (d) }\end{array}$} & \multicolumn{3}{c}{ Cumulative Change in Protein Content $(\%)$} \\
\cline { 2 - 4 } & Total & Myofibrillar & Sarcoplasmic \\
\hline 1 & $-0.3 \pm 0.6$ & $-0.3 \pm 0.4$ & $1.8 \pm 0.8$ \\
2 & $-5.6 \pm 0.4^{*}$ & $-5.3 \pm 0.4^{*}$ & $-1.5 \pm 0.9$ \\
3 & $-18.8 \pm 1.4^{*} \dagger$ & $-16.5 \pm 1.0^{*} \dagger$ & $1.2 \pm 0.8$ \\
4 & $-21.4 \pm 1.2^{*} \dagger$ & $-19.0 \pm 1.3^{*} \dagger$ & $1.7 \pm 0.7$ \\
5 & $-24.3 \pm 1.3^{*} \dagger$ & ND & ND \\
6 & $-27.2 \pm 1.9^{*} \dagger$ & ND & ND \\
\hline
\end{tabular}

NOTE. Protein content of the soleus was measured after indicated periods of unweighting; muscles from 10 to 15 animals were used for each time point. Myofibrillar and sarcoplasmic data were obtained from the same muscles. Protein accumulation in control animals averaged $5.2 \% \pm 0.5 \% / d$ for total (mixed) proteins, $4.4 \% \pm 0.4 \% / \mathrm{d}$ for myofibrillar proteins, and $4.9 \% \pm 0.5 \% / \mathrm{d}$ for sarcoplasmic proteins.

Abbreviation: ND, not determined in this experiment.

$* P<.05 \vee 1$ day of unweighting.

tP<.05 $P 2$ days of unweighting.

loss of total or myofibrillar proteins. By the end of 48 hours of unweighting, there was a small but significant loss of both total and myofibrillar proteins followed by considerable atrophy after 3 days. By calculating the difference in protein loss between days 2 and 3 of unweighting, the data show an average loss during the third day of $13.2 \%$ for total proteins and $11.2 \%$ for myofibrillar proteins, compared with only $5.3 \%$ and $5 \%$, respectively, for the second day. During the next 24 hours (day 4), this extent of protein loss decreased markedly to only about $2.6 \%$ and remained constant for at least up to 6 days' duration. Since days 5 and 6 did not differ from day 4 for the total proteins, measurements were not taken on these days for separate protein fractions. Thus, in terms of acute effects of unweighting on protein turnover in soleus muscle, the period between 48 and 72 hours is the most responsive in juvenile animals.

Unlike total and myofibrillar proteins, the sarcoplasmic protein pool showed neither significant loss nor accumulation at any time up to 4 days of unweighting. Thus the primary effect of unweighting on these proteins seems to be cessation of their further accumulation. Since the muscle as a whole undergoes atrophy, this response must represent a "sparing" of these proteins.

\section{IM Methodology for Protein Synthesis}

To facilitate measuring in vivo synthesis of separate sarcoplasmic and myofibrillar proteins, we used IM injection of $\left[{ }^{3} \mathrm{H}\right]$ phenylalanine. Since we were concerned that radioactive phenylalanine injected into the belly of the muscle might not diffuse rapidly to the far ends of the muscle, we analyzed the distribution of radioactivity between the middle $(\sim 50 \%)$ and the two ends of the muscle. Protein analysis showed $48 \% \pm 2 \%$ of the protein in the middle portion, but it contained $67 \% \pm 5 \%$ of the radioactivity. Consequently, in all subsequent measurements for protein synthesis by IM injection we used only the middle $(\sim 50 \%)$ of the muscle.

To assess protein synthesis rates using the IM injection technique, we analyzed intracellular phenylalanine specific activity. To do so, it was necessary to rid the muscle of its high level of interstitial radioactive phenylalanine. As described in the Methods, this was accomplished by washing muscles in cycloleucine. Concentrations of 20 and 100 mmol/L cycloleucine were compared. Both concentrations were equally effective in trapping phenylalanine within the cell but the higher concentration interfered with the $\beta$-phenethylamine assay; therefore $20 \mathrm{mmol} / \mathrm{L}$ cycloleucine was used. Two washes were deemed sufficient to effectively remove interstitial phenylalanine, since the second wash contained barely detectable amounts of radiolabeled phenylalanine.

\section{Total Mixed and Myofibrillar Protein Synthesis and Breakdown}

To assess contributions of protein synthesis and breakdown to the loss of total mixed and myofibrillar proteins, we measured in vivo protein synthesis in controls and at 24-hour intervals in unweighted muscle (Table 2). We then used these data and data for protein changes (Table 1) to calculate and compare estimated daily fractional rates of protein loss with protein synthesis and degradation.

Synthesis data for total proteins, obtained by IP injection of radiolabeled phenylalanine, showed a slower $(-35 \%)$ rate within 24 hours (Table 2). This rate of synthesis decreased further after 48 hours $(P<.05)$, and thereafter the rate leveled off. Although synthesis of myofibrillar proteins decreased over the same period of time, the magnitude of these changes differed. Rates of myofibrillar synthesis showed a steady decrease over the 4 days of unweighting, whereas total protein synthesis showed a somewhat sharper decrease over the first 2 days of unweighting. Nevertheless, by the end of 4 days of unweighting there was an appreciably lower fractional rate of both total $(-65 \%)$ and myofibrillar $(-50 \%)$ protein synthesis.

The rate of loss of myofibrillar and total proteins showed the sharpest decrease during the third day (11.2\% and $13.2 \%$, respectively; Table 1 ), with a much slower rate of loss during day $4(2.6 \%$ and $2.5 \%$, respectively). This diminished loss must be a consequence of a slowing of protein breakdown, as protein synthesis remained low. A comparison of daily protein changes and calculated fractional rates of protein breakdown illustrates this conclusion. Both total and myofibrillar proteins showed an increase in estimated protein breakdown over the first 3 days of unweighting (Table 2). Thereafter, protein breakdown decreased dramatically, thus accounting for the slower rate of protein loss. Therefore, qualitatively, total and myofibrillar protein breakdown increase during the time when the loss of these proteins is greatest.

\section{Sarcoplasmic Protein Synthesis and Breakdown}

Since sarcoplasmic proteins secm to be spared from appreciable loss during unweighting atrophy (Table 1), we also assessed synthesis and breakdown for this protein pool. Despite the preservation of these proteins, their rate of synthesis was significantly slower after 2 days of unweighting, decreasing steadily to $50 \%$ of cont rol values after 4 days of unweighting (Table 2 ). Comparative protein data showed 
Table 2. Effect of Unweighting on Fractional Rates of Synthesis and Degradation of Total, Myofibrillar, and Sarcoplasmic Proteins

\begin{tabular}{|c|c|c|c|c|c|c|}
\hline \multirow{3}{*}{$\begin{array}{c}\text { Duration of } \\
\text { Unweighting (d) }\end{array}$} & \multicolumn{6}{|c|}{ Fractional Rale $(\% / d)$} \\
\hline & \multicolumn{3}{|c|}{ Protein Synthesis } & \multicolumn{3}{|c|}{ Protein Degradation } \\
\hline & Total & Myotibrillar & Sarcoplasmic & Total & Myofibrillar & Sarcoplasmic \\
\hline 0 & $18.4 \pm 0.8$ & $10.4 \pm 0.4$ & $10.0 \pm 0.3$ & 13.2 & 6.0 & 5.1 \\
\hline 1 & $12.7 \pm 0.7^{*}$ & $8.8 \pm 0.5$ & $8.6 \pm 0.5$ & 13.0 & 9.1 & 6.8 \\
\hline 2 & $8.9 \pm 0.9^{*}+$ & $7.8 \pm 0.2^{*}$ & $7.2 \pm 0.5^{*}$ & 14.2 & 12.9 & 10.5 \\
\hline 3 & $7.0 \pm 0.6^{*} \dagger$ & $6.3 \pm 0.2^{*}+\ddagger$ & $5.9 \pm 0.2^{*} \dagger$ & 20.2 & 17.5 & 3.2 \\
\hline 4 & $6.5 \pm 0.5^{* \dagger}$ & $5.2 \pm 0.2^{*}+\ddagger$ & $4.9 \pm 0.2^{*} † \ddagger$ & 9.1 & 7.7 & 4.4 \\
\hline 5 & $7.3 \pm 0.7^{*} \dagger$ & ND & ND & 10.2 & ND & ND \\
\hline 6 & $5.6 \pm 0.8^{*} \dagger$ & ND & ND & 8.5 & ND & ND \\
\hline
\end{tabular}

NOTE. Fractional rates of protein synthesis were determined in soleus muscles of control animals (zero days of unweighting) and animals that were hindlimb-suspended for 1 to 6 days. Muscles were excised from 10 to 15 animals per time point. Rates for total mixed proteins were obtained using the IP injection method and for myofibrillar and sarcoplasmic proteins by the IM injection method, as described in the Methods. Total mixed protein data were collected from the same muscles used to assess protein content. Myofibrillar and sarcoplasmic data were obtained from muscles other than those used for analyzing protein content. Fractional rates of protein degradation were calculated as synthesis minus growth rate, as described in the Methods.

Abbreviation: ND, not determined in this experiment

$* P<.05 v$ control.

$\dagger P<.05 \vee 1$ day of unweighting.

$\pm P<.05 \vee 2$ days of unweighting.

a parallel decrease in the fractional rate of protein accretion through day 2; however, this trend was reversed for days 3 and 4 .

Since changes in synthesis of sarcoplasmic proteins did not parallel the pattern for the content of this protein pool, only a decrease in protein breakdown could explain the results (Table 2). The pattern for breakdown of sarcoplasmic proteins showed a modest increase over the first 2 days of unweighting, followed by a sharp decrease in the rate of degradation during days 3 and 4 . The breakdown of sarcoplasmic proteins was consistently slower than that for myofibrillar proteins; also, the pattern for sarcoplasmic proteins differs from that for myofibrillar proteins.

\section{DISCUSSION}

It is evident from these results that acute changes in protein synthesis and degradation in response to unweighting vary depending on the time period over which measurements are made. Therefore, a daily time course study using juvenile animals was essential for evaluating relative contributions of synthesis and degradation to unweighting atrophy of developing muscle. Earlier studies in which only certain early time points were selected did not provide a complete picture of the sequence of events. ${ }^{1.2}$ The only other extensive time course studies used adult rats and longer periods of unweighting of 24 to 56 days' duration. ${ }^{4.11}$

\section{Loss of Myofibrillar Proteins}

Data presented here show that in juvenile animals unweighting caused a rapid decrease in total and myofibrillar proteins up to day 3, with a slower rate of loss thereafter. In contrast, in adult animals myofibrillar protein loss does not occur until about 1 week. ${ }^{4,11}$ Hence these findings show an important fundamental difference in the response of developing and adult muscle to unweighting. Developing soleus muscle achieves a peak rate of myofibrillar loss more quickly, but also attenuates this rate of loss more rapidly.

One possible reason for the reduced rate of myofibrillar protein loss is that factors responsible for promoting muscle growth may afford some protection against sustained rapid unweighting atrophy in the juvenile animal. We have found that plantaris and gastrocnemius muscles of these animals show reduced growth but not atrophy for up to 12 days of unweighting. ${ }^{5}$ In contrast, in adult animals, size, amount of myofibrillar protein, and cross-sectional fiber area for gastrocnemius and plantaris muscles were diminished following 5 to 28 days of hindlimb suspension. ${ }^{26.30}$ Therefore care must be taken in making comparisons between hindlimb unweighting of juvenile and adult animals.

It is evident from these data that the most substantial acute loss of protein in the juvenile soleus muscle occurs during the third day of unweighting (Table 1). Thereafter, the extent of protein loss is far less, due to a marked decrease in protein breakdown (Table 2). This event coincides with the time at which soleus muscle becomes more responsive to insulin in terms of in vitro glucose transport, protein synthesis and breakdown, ${ }^{31,32}$ and in vivo glucose transport. ${ }^{33}$ Hence it is conceivable that an increased response of protein breakdown to insulin could slow muscle atrophy at this time point.

We also cannot rule out a potential role of enhanced $\beta$-adrenergic activity, which has been demonstrated in the unweighted soleus muscle. ${ }^{16,34}$ Recent studies with clenbuterol, a selective $\beta_{2}$-agonist, demonstrated that its anabolic effect on skeletal muscle may involve a slowing of myofibrillar protein degradation. ${ }^{35}$ Therefore increased responsiveness of the unweighted muscle to circulating catecholamines could contribute to the decreased loss of myofibrillar proteins due to a slowing of their degradation. 


\section{Sparing of Sarcoplasmic Proteins}

One major finding of this study is that unwcighting atrophy is characterized by a sparing of sarcoplasmic proteins. As membrane proteins form a portion of these proteins, it would be expected that membrane receptors should be spared coincident with the sparing of this pool of proteins; a number of studies support this idea. In vitro insulin effects on metabolism, ${ }^{31,32}$ and in situ insulin stimulation of glucose transport ${ }^{33}$ or inhibition of cyclic adenosine monophosphate accumulation, ${ }^{16}$ are greater in unweighted than in normal musclc. These elevated responses to insulin have been attributed to an increased density of receptors in the plasma membrane as a consequence of no decrease in the total pool of receptors during unweighting atrophy. ${ }^{15}$ A series of studies have also been conducted concerning $\beta$-adrenergic responses. Unweighting the soleus for 3 to 6 days shows an increased ability both in vitro and in situ for isoproterenol, a $\beta$-agonist, to increase glycogen breakdown, decrease glycogen formation, and enhance the production of cyclic adenosine monophosphate. ${ }^{16,34}$ This increased response to the $\beta$-agonist was a consequence of an increased binding capacity of the $\beta$-adrenergic receptor relative to muscle size. ${ }^{16}$ Just as with the insulin receptor, there was no loss of $\beta$-adrenergic receptors despite significant atrophy of the muscle. Thus several lines of evidence support the idea that unweighting atrophy of juvenile soleus muscle is a consequence of the specific loss of myofibrillar rather than sarcoplasmic proteins.

Sparing of sarcoplasmic proteins is not related to synthesis of these proteins; instead, the synthesis of myofibrillar and sarcoplasmic proteins decreased in parallel. When synthesis data (Table 2) were evaluated by linear regression analysis as fractional rate versus time, slopes of the plots were similar $(-2.67 \% / \mathrm{d}$ myofibrillar, $-2.65 \% / \mathrm{d}$ sarcoplasmic) with a high degree of correlation $\left(R^{2}=.99\right.$ for both plots). In contrast to this linear relationship, studies with unweighted adult soleus muscle showed a much more rapid and exponential decrease in the rate of myofibrillar synthe- sis. ${ }^{4}$ Indeed, the fractional rate of synthesis in the adult muscle decreased by approximately $50 \%$ in less than 2 days, whereas in this study with juvenile muscle the rate of myofibrillar protein synthesis decreased more slowly (Table 2 ). In contrast to synthesis of myofibrillar proteins, formation of total mixed proteins decreased more rapidly. The reason for this discrepancy cannot be firmly established; still, it is clear that there are important fundamental differences in the effect of unweighting on synthesis of myofibrillar proteins in juvenile and adult muscle.

Sparing of sarcoplasmic proteins undoubtedly must be a consequence of a parallel decrease in their synthesis and breakdown despite an increased degradation of myofibrillar proteins. Such a conclusion points to a fundamental difference in the control of degradation of these two protein pools. Indeed, a number of investigators have concluded that breakdown of myofibrillar and nonmyofibrillar (including sarcoplasmic) proteins is regulated independently. ${ }^{35-39}$

In a previous study, we concluded that unweighting atrophy does not involve lysosomal proteolysis. Instead, cytoplasmic proteolysis, perhaps involving $\mathrm{Ca}^{2+}$ - and/or thiol-dependent processes, is responsible for the accelerated degradation. ${ }^{22}$ Together with data from the current study, one can infer that the accelerated myofibrillar protein breakdown is cytosolic in origin. While some published data support this idea, ${ }^{35} \mathrm{~N}$-ethylmaleimide modification of myofibrillar proteins leads to their degradation in lysosomes. ${ }^{40}$ Similar controversy exists for the site of degradation of nonmyofibrillar (sarcoplasmic) proteins. Membrane proteins are reportedly degraded primarily in the lysosome. ${ }^{41-43}$ In contrast, the exercise-induced increase in protein degradation seems to be due to the loss of nonmyofibrillar proteins via a nonlysosomal pathway. ${ }^{44}$

\section{ACKNOWLEDGMENT}

The technical assistance of Wendy Hartshorne is recognized. Dr Erik J. Henriksen's comments on the manuscript were appreciated.

\section{REFERENCES}

1. Goldspink DF, Morton AJ, Loughna P, et al: The effect of hypokinesia and hypodynamia on protein turnover and the growth of four skeletal muscles of the rat. Pflugers Arch 407:333-340, 1986

2. Loughna P, Goldspink G, Goldspink DF: Effect of inactivity and passive stretch on protein turnover in phasic and postural rat muscles, J Appl Physiol 61:173-179, 1986

3. Jaspers SR, Fagan JM, Satarug S, et al: Effects of immobilization on rat hind limb muscles under non-weight-hearing conditions. Muscle Nerve 11:458-466, 1988

4. Thomason DB, Biggs RB, Booth FW: Protein metabolism and $B$-myosin heavy-chain mRNA in unweighted soleus muscle. Am J Physiol 257:R300-R305, 1989

5. Jaspers SR, Tischler ME: Atrophy and growth failure of rat hindlimb muscles in tail-cast suspension. J Appl Physiol 57:14721479,1984

6. Jaspers SR, Tischler ME: Role of glucocorticoids in the response of rat leg muscles to reduced activity. Muscle Nerve $9.554-561,1986$
7. Thomason DB, Booth FW: Atrophy of the soleus muscle by hindlimb unweighting. J Appl Physiol 68:1-12, 1990

8. Steffen JM, Musacchia XJ: Disuse atrophy, plasma corticosterone, and muscle glucocorticoid receptor levels. Aviat Space Environ Med 58:996-1000, 1987

9. Jaspers SR, Henriksen EJ, Jacob S, et al: Metabolism of branched-chain amino acids in leg muscles from tail-cast suspended intact and adrenalectomized rats. Metabolism 38:109-114, 1989

10. Desplanches D, Kayar SR, Sempore B, et al: Rat soleus muscle ultrastructure after hindlimb suspension. J Appl Physiol 69:504-508, 1990

11. Thomason DB, Herrick RE, Surdyka D, et al: Time course of soleus muscle myosin expression during hindlimb suspension and recovery. J Appl Physiol 63:130-137, 1987

12. Tsika RW, Herrick RE, Baldwin KM: Effect of anabolic steroids on skeletal muscle mass during hindlimb suspension. J Appl Physiol 63:2122-2127, 1987

13. Thomason DB, Herrick RE, Baldwin KM: Activity influ- 
ences on soleus muscle myosin during rodent hindlimb suspension. J Appl Physiol 63:138-144, 1987

14. Jaspers SR, Fagan JM, Tischler ME: Biochemical response to chronic shortening in unloaded soleus muscles. J Appl Physiol 59:1159-1163, 1985

15. Henriksen EJ, Tischler ME, Johnson DG: Increased response to insulin of glucose metabolism in the 6-day unloaded rat soleus muscle. J Biol Chem 261:10707-10712, 1986

16. Kirby CR, Woodman CR, Woolridge D, et al: Cyclic AMP accumulation and $\beta$-adrenergic binding in unweighted and denervated rat soleus muscle. Metabolism 41:793-799, 1992

17. Garlick PJ, McNurlan MA, Preedy VR: A rapid and convenient technique for measuring the rate of protein synthesis in tissues by injection of $\left[{ }^{3} \mathrm{H}\right]$ phenylalanine. Biochem J 192:719-723, 1980

18. Jepson MM, Pell JM, Bates PC, et al: The effects of endotoxaemia on protein metabolism in skeletal muscle and liver of fed and fasted rats. Biochem J 235:329-336, 1986

19. Perry BN: Protein turnover in skeletal muscle of piglets. $\mathrm{Br} \mathbf{J}$ Nutr 31:35-45, 1974

20. Fulks RM, Li JB, Goldberg AL: Effects of insulin, glucose and amino acids on protein turnover in rat diaphragm. $J$ Biol Chem 250:290-298, 1975

21. Lowry OH, Rosebrough NJ, Farr AL, et al: Protein measurement with the Folin reagent. J Biol Chem 193:265-275, 1951

22. Tischler ME, Rosenberg S, Satarug S, et al: Different mechanisms of increased proteolysis in atrophy induced by denervation or unweighting of rat soleus muscle. Metabolism 39:756-763, 1990

23. Gerard KW, Jacobs JW, Schneider DL: Rate of degradation of muscle proteins following localized radiolabeling with $\mathrm{N}$-ethylmaleimide in vivo. Arch Biochem Biophys 181:94-102, 1977

24. Gornall AJ, Bardawill CJ, David MM: Determination of serum proteins by means of the biuret reaction. $J$ Biol Chem 177:751-766, 1949

25. Maroni BJ, Karapanos G, Mitch WE: System ASC and sodium-independent neutral amino acid transport in muscle of uremic rats. Am J Physiol 251:F81-F86, 1986

26. Musacchia XJ, Steffen JM, Deavers DR: Rat hindlimb muscle responses to suspension hypokinesia/hypodynamia. Aviat Space Environ Med 54:1015-1020, 1983

27. Reiser PJ, Kasper CE, Moss RL: Myosin subunits and contractile properties of single fibers from hypokinetic rat muscles. J Appl Physiol 63:2293-2300, 1987

28. Roy RR, Bello MA, Bouissou P, et al: Size and metabolic properties of fibers in rat fast-twitch muscles after hindlimb suspension. J Appl Physiol 62:2348-2357, 1987

29. Michel RN, Olha AE, Gardiner PF: Influence of weight bearing on the adaptations of rat plantaris to ablation of its synergists. J Appl Physiol 67:636-642, 1989
30. Graham SC, Roy RR, Hauschka EO, et al: Effects of periodic weight support on medial gastrocnemius fibers of suspended rats. J Appl Physiol 67:945-953, 1989

31. Henriksen EJ, Tischler ME: Time course of the response of carbohydrate metabolism to unloading of the soleus. Metabolism 37:201-208, 1988

32. Tischler ME, Satarug S, Eisenfeld SH, et al: Insulin effects in denervated and non-weight-bearing rat soleus muscle. Muscle Nerve 13:593-600, 1990

33. Henriksen EJ, Ritter LS, Munoz KA, et al: Enhanced effect of insulin-like factors on glucose transport activity in the unweighted rat soleus muscle. ASGSB Bull 6:93, 1992 (abstr)

34. Kirby CR, Tischler ME: $\beta$-Adrenergic effects on carbohydrate metabolism in the unweighted rat soleus muscle. J Appl Physiol 69:2113-2119, 1990

35. Lowell BB, Ruderman NB, Goodman MN: Evidence that lysosomes are not involved in the degradation of myofibrillar proteins in rat skeletal muscle. Biochem J 234:237-240, 1986

36. Li JB, Wassner SJ: Effects of food deprivation and refeeding on total protein and actomyosin degradation. Am $\mathbf{J}$ Physiol 246:E32-E37, 1984

37. Smith DM, Sugden PH: Contrasting response of protein degradation to starvation and insulin as measured by release of $N^{\mathrm{s}}$-methylhistidine or phenylalanine from the perfused rat heart. Biochem J 237:391-395, 1986

38. Kayali AG, Young VR, Goodman MN: Sensitivity of myofibrillar proteins to glucocorticoid-induced muscle proteolysis. Am J Physiol 252:E621-E626, 1987

39. Goodman MN: Differential effects of acute changes in cell $\mathrm{Ca}^{2+}$ concentration on myofibrillar and non-myofibrillar protein breakdown in the rat extensor digitorum longus muscles in vitro. Assessment by production of tyrosine and $N^{s}$-methylhistidine. Biochem J 241:121-127, 1987

40. Gerard KW, Schneider DL: Evidence for degradation of myofibrillar proteins in lysosomes. Myofibrillar proteins derivatized by intramuscular injection of $N$-ethylmaleimide are sequestered in lysosomes. J Biol Chem 254:11798-11805, 1979

41. Libby P, Goldberg AL: Comparison of the control and pathways for the degradation of the acetylcholine receptor and average proteins in cultured muscle cells. J Cell Physiol 107:185194,1981

42. Hare JF: Dissection of membrane protein degradation mechanisms by reversible inhibitors. J Biol Chem 263:8759-8764, 1988

43. Creek KE, Sly WS: Biosynthesis and turnover of the phosphomannosyl receptor in human fibroblasts. Biochem J 214:353-360, 1983

44. Kasperek GJ, Snider RD: Total and myofibrillar protein degradation in isolated soleus muscles after exercise. Am J Physiol 257:E1-E5, 1989 